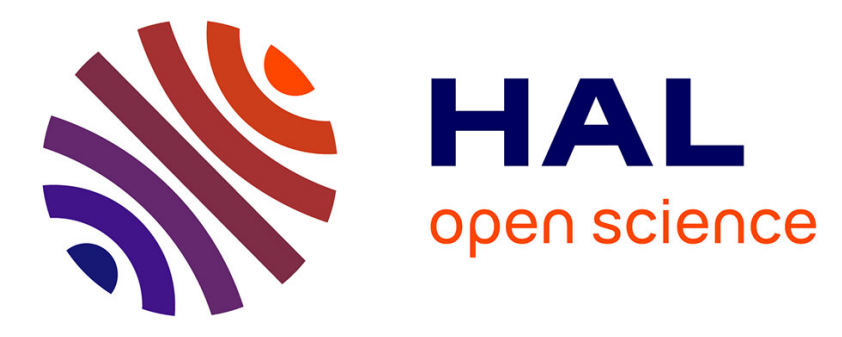

\title{
Dynamic Viscosity of Purified Multi-Walled Carbon Nanotubes Water and Water-Propylene Glycol-Based Nanofluids
}

Samah Hamze, Nawal Berrada, Alexandre Desforges, Brigitte Vigolo, Jerome Gleize, Jaafar Ghanbaja, Thierry Mare, David Cabaleiro, Patrice Estellé

\section{To cite this version:}

Samah Hamze, Nawal Berrada, Alexandre Desforges, Brigitte Vigolo, Jerome Gleize, et al.. Dynamic Viscosity of Purified Multi-Walled Carbon Nanotubes Water and WaterPropylene Glycol-Based Nanofluids. Heat Transfer Engineering, 2021, 42 (19-20), pp.1663-1674. 10.1080/01457632.2020.1818382 . hal-02958233

\section{HAL Id: hal-02958233 https://hal.science/hal-02958233}

Submitted on 26 Nov 2020

HAL is a multi-disciplinary open access archive for the deposit and dissemination of scientific research documents, whether they are published or not. The documents may come from teaching and research institutions in France or abroad, or from public or private research centers.
L'archive ouverte pluridisciplinaire HAL, est destinée au dépôt et à la diffusion de documents scientifiques de niveau recherche, publiés ou non, émanant des établissements d'enseignement et de recherche français ou étrangers, des laboratoires publics ou privés. 
Dynamic viscosity of purified multi-walled carbon nanotubes water and waterpropylene glycol based nanofluids

Samah Hamze ${ }^{\mathrm{a}}$, Nawal Berrada ${ }^{\mathrm{b}}$, Alexandre Desforges ${ }^{\mathrm{b}}$, Brigitte Vigolo ${ }^{\mathrm{b}}$, Jérôme Gleize $^{\mathrm{b}}$, Jaafar Ghanbaja ${ }^{\mathrm{b}}$, Thierry Maréa ${ }^{\text {, David Cabaleiro }}{ }^{\mathrm{a}, \mathrm{c}}$ and Patrice Estelléa,*

${ }^{a}$ Univ Rennes, LGCGM, 35704 Rennes, France; ${ }^{b}$ Institut Jean Lamour, CNRS-Univ Lorraine, 54000 Nancy, France; ${ }^{c}$ Departamento de Física Aplicada, Universidade de Vigo, 36310 Vigo, Spain

*corresponding author: patrice.estelle@univ-rennes1.fr; Tel.: +33-(0)23234200 


\title{
Dynamic viscosity of purified multi-walled carbon nanotubes water and water- propylene glycol based nanofluids
}

\begin{abstract}
We report in this study the experimental investigation of the dynamic viscosity of purified multi-walled carbon nanotubes (MWCNT) water and water-propylene glycol based nanofluids in the temperature range $10-80{ }^{\circ} \mathrm{C}$. Four weight concentrations of MWCNTs are considered, between 0.005 and 0.1 wt.\%. Triton X-100, a common nonionic surfactant, is used to disperse the nanotubes and stabilize the nanofluids as evidenced by optical characterization. Purified and non-damaged MWCNTs are used for nanofluid preparation by the two-step method. MWCNT characterization is deeply investigated from a set of complementary techniques such as thermogravimetric analysis, transmission electron microscopy and Raman spectroscopy. The studied nanofluids behave as Newtonian fluids for low nanotube content while a shear-thinning behavior is noticed for higher concentration. Finally, the viscosity enhancement of nanofluids with MWCNT loading is compared to the modified Maron-Pierce model considering the presence of aggregates and their size obtained from optical observations.
\end{abstract}

Keywords: MWCNTs, water-based nanofluids, dynamic viscosity, effect of temperature and concentration

\section{Introduction}

The development of nanofluid research for different application fields as alternative energy, medicine, heat transfer, electronics and microelectronics, air conditioning, transportation, concentrating solar energy, and micro-channel cooling is continuously growing [1]. This interest comes from the wide selection of nanomaterials having superior intrinsic thermal properties such as carbon nanomaterials: nanodiamonds, carbon nanotubes, graphene, and graphene quantum dots. Introduced within common base fluids, these nanoparticles have been proven to enhance heat transfer properties of such nanofluids. Hence, the investigation of these systems has widely attracted the recent research in the nanofluid field. In this context, carbon nanomaterials such as multi-walled carbon nanotubes (MWCNTs) are especially promising. Among the different thermophysical 
properties, viscosity is very important to be investigated since most of the applications related to heat transfer involve fluid flow [2]. For instance, the understanding of thermo-fluidic behavior, pressure drop and pumping power of flow systems working with nanofluids is directly related to the rheology of these heat transfer fluids. Researchers have paid more attention to thermal conductivity studies of carbon-based nanofluids than to their viscosity behavior. Hence, the studies on the dynamic viscosity of carbon nanotubes (CNT) nanofluids were limited in comparison to other nanofluids [3]. However, this topic is now raising a growing attention and its investigation can be beneficial for the performance evaluation of CNT nanofluids with regards to their potential applications [4]. It was previously reported that the rheological behavior of MWCNT-based nanofluids is influenced by several parameters such as the nature of the base fluid, the nanomaterial concentration, the presence of surfactant and the temperature used. Thus, Halelfadl et al. [5] reported the influence of concentration (0.0055-0.55 vol.\%) and temperature $\left(0-40{ }^{\circ} \mathrm{C}\right)$ on the viscosity of MWCNT-based nanofluids in water. A Newtonian behavior was noticed for MWCNT loadings below 0.055 vol.\%, while a shear-thinning behavior was observed for higher nanoparticle contents. Increase of nanofluids viscosity with concentration was also correlated to the presence of aggregates. MWCNTs dispersed in water-ethylene glycol mixture at two weight concentrations, 0.015 and $0.15 \%$, were investigated in the low shear rate region (up to $10 \mathrm{~s}^{-1}$ ) by Kaman et al. [6]. Within the analyzed conditions, the authors evidenced a strong shear-thinning effect for the high concentration, while the other one was Newtonian. Hameed et al. [7] studied the case of 0.1 wt.\% of MWCNT-Kapok seed oil based nanofluid. A non-Newtonian behavior was found for this nanofluid with an increase in viscosity in comparison to oil base fluid [7]. The viscosity of pure heat transfer oil and MWCNT-oil nanofluid with CNT weight concentrations of $0.05 \%, 0.1 \%$, and $0.2 \%$ was also measured in [8], considering the influence of temperature. In addition, Babita et al. [9] dispersed both pristine and 
functionalized MWCNTs in water with a mixture of sodium dodecyl benzene sulfonate and gum arabic (50:50 ratio by weight). From the performed rheological measurements, they showed that these nanofluids were Newtonian with a slight increase in viscosity compared to water in the shear rate range of 10-1000 s $\mathrm{s}^{-1}$ and at room temperature. On the other hand, Jabbari et al. [10] investigated the viscosity of single-walled carbon nanotube based nanofluids in water by equilibrium molecular dynamics simulation, between 25 and $65^{\circ} \mathrm{C}$ and with different volume fractions in the range of 0.125-0.734 vol.\%. Their results showed that viscosity had risen with increasing the volume fraction of nanoparticles and with decreasing temperature. Viscosity of nanofluids with chemically treated carbon nanotubes (CNTs) dispersed in ethylene glycol were studied in the concentration range from 0.12 to $0.4 \mathrm{wt} \%$ and temperature range of $25^{\circ} \mathrm{C}$ to $60^{\circ} \mathrm{C}$ in [11]. A Newtonian behaviour was reported for these nanofluids with an increase in viscosity with CNT content. A bottom up approach was developed in [12] to evaluate the best trade-off between thermal conductivity and viscosity increases for different carbon-based nanofluids, including CNT and graphene nanosheets. Such an approach was originally based on Prandtl number evaluation. More recently, the rheological behavior of different carbon-based nanomaterials dispersed in an ethylene glycol:water mixture 50:50 vol.\% was investigated for a content varying between 0.25 and $2.0 \mathrm{wt} \% \%$ and temperature from 10 to $80{ }^{\circ} \mathrm{C}$ [13]. A shear-thinning behavior of the nanofluids was mainly noticed and a theoretical correlation was proposed to explain the viscosity enhancement of the nanofluids with the particle loading, temperature and base fluid viscosity. Lastly, MWCNT/PEG-400 nanofluids as potential nanoenhanced heat transfer and storage media were studied by Marcos et al. [14]. They reported a shear rate dependence of dynamic viscosity for the base fluid and nanofluids in the $15-70{ }^{\circ} \mathrm{C}$ and 0.01 1 wt.\% of nanotube content ranges. The viscosity enhancement of nanofluids with the nanotube content was also compared to several theoretical models. 
As a contribution on the role of CNTs in dynamic viscosity of nanofluids, the present study aims at preparing purified MWCNT nanofluids dispersed in water and Tyfocor® LS - a commercial mixture of propylene-glycol:water (around 40:60 wt.\%) [15] - and to investigate their dynamic viscosity at different temperatures. Four weight concentrations of MWCNTs were considered, between 0.005 and 0.1 wt.\%. Triton X-100, a common nonionic surfactant was used to disperse the nanotubes and stabilize the nanofluids. The raw and the purified MWCNTs were characterized by using thermogravimetric analysis (TGA), transmission electron microscopy (TEM) and Raman spectroscopy. Then, optical microscopy technique allowed to analyze the nanofluid dispersion state in the two base fluids and to select the surfactant concentration showing an homogeneous dispersion state. Finally, the results of the dynamic viscosity of the prepared nanofluids are presented and discussed with regard to the presence of the surfactant, the type of the base fluid, the nanotube concentration and the applied temperature.

\section{Materials and methods}

The raw commercial MWCNTs (rCNT) were purchased from Nanocyl S.A. (Nanocyl ${ }^{\mathrm{TM}}$ NC7000, Sambreville, Belgium). The average dimensions of MWCNTs were diameter $9.2 \mathrm{~nm}$ and length $~ 1.5 \mu \mathrm{m}$; the density of MWCNTs was considered about $1.8 \mathrm{~g} / \mathrm{cm}^{3}$ [16]. The carried-out purification method was a one-pot gas-phase treatment [17]. To be brief, the rCNT, deposited on a silica crucible, were introduced in a tubular oven. After purging air from the set-up, the sample was heated at $10{ }^{\circ} \mathrm{C} / \mathrm{min}$ up to $1000{ }^{\circ} \mathrm{C}$ under a stream of chlorine at a flow-rate of $200 \mathrm{~mL} / \mathrm{min}$ for $2 \mathrm{~h}$. After this treatment, the MWCNT powder was maintained at same temperature for 2 additional hours under nitrogen and the MWCNT sample cooled down naturally. These purified MWCNTs (pCNT) were used to produce water and water-propylene glycol (Tyfocor ${ }^{\circledR}$ LS) [18] based nanofluids by the two-step method with four nanoparticle concentrations: 0.005, 0.01, 0.05, 0.1 wt.\% and Triton X- 
100 (purchased from Sigma Aldrich) as surfactant [19]. Different amounts of surfactant were initially tested, from 0.1 to $10 \mathrm{wt} . \%$, with the higher weight concentration in nanotubes. The best surfactant content, 5 wt.\%, was finally selected based on dispersion effectiveness evaluated from optical microscopy analysis as it will be described later in Figure 2. This content was further used for all the investigated concentrations in nanotubes. For the dispersion procedure, $1 \mathrm{~h}$ of ultrasonication (probe sonicator, $125 \mathrm{~W}$ with a pulse mode $2 \mathrm{~s}$ ON/1 s OFF) was used for all the nanofluids by controlling the temperature of samples to avoid evaporation.

TGA was used to quantify the amount of metal-based impurities, corresponding to the residual weight (oxidized metals) at $900{ }^{\circ} \mathrm{C}$, after combustion of the MWCNTs. The used apparatus was a Setaram Setsys evolution 1750 (Setaram Instrumentation, Caluire, France). Typically, about 5 mg of the raw or the purified MWCNT powder were loaded in a platinum crucible and transferred in the TGA chamber. Temperature was increased from room temperature to $900{ }^{\circ} \mathrm{C}$ with a ramp of 5 ${ }^{\circ} \mathrm{C} / \mathrm{min}$ under a dry air flow-rate of $20 \mathrm{~mL} / \mathrm{min}$.

A JEM-ARM 200F apparatus (JEOL Ltd., Tokyo, Japan) at an accelerating voltage of $80 \mathrm{kV}$ was used for TEM observations. The MWCNT powder was dispersed in ethanol using a sonication bath for a few minutes and a drop of this dispersion was deposited on a holey carbon grid (200 mesh size). About 30 images were taken at different areas for each sample to guarantee a statistical analysis.

For Raman spectroscopy analysis, a LabRAM HR 800 micro-Raman spectrometer (HR LabRam invers, Jobin-Yvon-Horiba, Bensheim, Germany) was used with a red incident laser ( $\lambda=$ $632.8 \mathrm{~nm}$ ) and an x50 objective. A dispersion in ethanol of the raw or purified MWCNTs was deposited on a glass slide. At least 3 spectra were recorded for each sample. The ratio of the peak 
intensity I of the $\mathrm{D}$ band to that of the $\mathrm{G}$ band, $\mathrm{I}_{\mathrm{D}} / \mathrm{I}_{\mathrm{G}}$, was calculated by dividing the height of the $\mathrm{D}$ band by that of the $\mathrm{G}$ band. The precision of the data was calculated from the standard deviation to the $\mathrm{I}_{\mathrm{D}} / \mathrm{I}_{\mathrm{G}}$ average.

Optical microscopy observations were carried out with an Olympus TH4-200 BXS1 microscope (Olympus Optical Co., Ltd., Tokyo, Japan) with an x10 objective. For the observations, a drop of a MWCNT nanofluid was deposited on a glass slide and covered by a coverslip.

Viscosity measurements were performed between 0 and $80^{\circ} \mathrm{C}$ using a Malvern Kinexus Pro rheometer (Malvern instruments, United Kingdom) working with a cone-plate geometry appropriate for studying low-viscous samples, with a cone angle of $1^{\circ}$, a diameter of $60 \mathrm{~mm}$ and a gap of 0.03 mm. The sample temperature was stabilized with an accuracy of $0.01^{\circ} \mathrm{C}$ by a heating plate and Peltier temperature control system located below the lower plate. The entire geometry was enclosed under a special cover to avoid evaporation problems and confine the sample to a controlled environment. Before starting experiments and to ensure uniform initial temperature conditions, the sample was maintained at the tested temperature for five minutes. The shear viscosity-shear rate flow curves were defined in the shear rate region from 10 to $1000 \mathrm{~s}^{-1}$ using shear stress-controlled tests under steadystate condition. The tests were repeated at least twice to ensure the reproducibility of the measurement and the stability of the nanofluids over time. Additional details about the experiments with this instrument can be found in refs. [5,20].

\section{Results and discussion}

Chemical modification of MWCNTs and dispersion in the base fluids

As mentioned earlier, the used rCNTs were produced by chemical vapor deposition. The CNT 
growth was assisted by Co and Fe used as catalysts. It is well-known that these metal-based particles from these catalysts remain in the CNT samples [21]. Figure 1a shows typical TEM images of the raw MWCNTs. The metal-based particles appear darker compared to the MWCNT walls (straight parallel lines) due to the higher electron density of these catalyst-based particles.

The content of the metal-based impurities in both the raw and purified MWCNTs was quantified by TGA. The used rCNT sample contained $10.90 \mathrm{wt} \%$ of metallic impurities. These noncarbon impurities needed to be removed before nanofluid preparation. The used purification method was highly selective towards metallic impurities, which induced both high purification yield and preservation of MWCNT structural quality [14]. Under the optimized conditions, i.e. thermal treatment at $1000^{\circ} \mathrm{C}$ under $\mathrm{Cl}_{2}$ for $2 \mathrm{~h}$ and under $\mathrm{N}_{2}$ for 2 additional hours, the yield of metal-based impurity removal reaches $100 \%$. Indeed, at the accuracy of TGA measurements, the used pCNTs are free of metallic impurities. No metallic impurity was observed by TEM in the MWCNT sample after purification (Figure 1b). The structural quality of both rCNT and pCNT was investigated by Raman spectroscopy. The intensity of the $\mathrm{D}$ band (around $1330 \mathrm{~cm}^{-1}$ ) is known to increase in comparison with that of the G band (around $1590 \mathrm{~cm}^{-1}$ ) when defects are introduced in the MWCNT walls [19]. The $I_{D} / I_{G}$ ratio of the rCNTs is $1.9 \pm 0.1$ and that of the pCNTs is $1.6 \pm 0.1$ meaning that they have not been damaged by the applied purification treatment and the CNT dimensions were not modified, as shown in Figure 1.

Addition of Triton X-100, which is a surfactant known to efficiently disperse CNTs [23], was used for nanofluid preparation. As mentioned earlier, several amounts of surfactant with $0.1 \mathrm{wt}$ \% of pCNT were initially tested. It can be deduced from the optical images shown in Figure 2 that the dispersion state of CNTs depend on the surfactant content under a similar ultrasonic procedure for nanofluid preparation. Higher the content surfactant, better the dispersion state of the MWCNTs. 
Large aggregates are present within the nanofluid for both heat transfer fluids until reaching 5 wt.\% in Triton X-100. Increasing this content up to $10 \mathrm{wt} . \%$ did not lead to any improvement in the dispersion state. Based on this finding, the nanofluids investigated in this study for their shear flow behaviour and viscosity were produced with 5 wt.\% in Triton X-100 for both heat transfer fluids and all the MWCNT concentrations studied.

With this relatively high concentration of surfactant, both good dispersion and stability were achieved, as shown from visual observation of the samples after one month at rest, see Figure 3. However, for the selected content of surfactant (5 wt.\% Triton X-100), it was observed that nanotube aggregates remain visible in the optical microscopy images (Figure 2). Their number are greater when Tyfocor ${ }^{\circledR}$ LS was used as base fluid compared with water. The size measurement was evaluated for both nanofluids on around 40 aggregates. The mean size is of $4 \mu \mathrm{m} \pm 1 \mu \mathrm{m}$ and $3 \mu \mathrm{m}$ $\pm 1 \mu \mathrm{m}$ for the MWCNT based nanofluid with water and Tyfocor ${ }^{\circledR}$ LS (5 wt.\% Triton X-100), respectively; meaning that the aggregate size was not significantly modified by the used solvent.

\section{Shear flow behavior and dynamic viscosity of base fluids and nanofluids} Effect of surfactant

The effectiveness of the experimental procedure has first been validated by performing measurements with distilled water between 10 and $40{ }^{\circ} \mathrm{C}$. Tyfocor ${ }^{\circledR}$ LS liquid was also tested as a calibration fluid between 0 and $80^{\circ} \mathrm{C}$ in order to validate the experimental protocol described above. Then, to evaluate the effect of surfactant on the flow properties of the liquids used for nanofluid preparation, experiments were performed, for each solvent, in the presence of 5 wt.\% of Triton X100. 
As expected, water and Tyfocor® ${ }^{\circledR}$ LS thermal fluid were Newtonian at all studied temperatures, as evidenced in Figure 4 for two temperatures, with a decrease in viscosity with temperature as expected. In order to confirm the accuracy of the used experimental protocol, the viscosity values obtained for water (between 10 and $40^{\circ} \mathrm{C}$ ) and Tyfocor® LS thermal fluid (between 0 and $80^{\circ} \mathrm{C}$ ) were compared with available literature/reference data. For distilled water, an absolute average deviation (AAD) about $3.5 \%$ was obtained in comparison to the well-known literature values in the $10-40{ }^{\circ} \mathrm{C}$ range [24]. With Tyfocor ${ }^{\circledR}$ LS fluid, the AAD was less than $5 \%$ compared to the values given by the manufacturer in the tested temperature range [18]. It should be noted that in the manufacturer datasheet there was no description of the experimental procedure that was followed for viscosity measurements.

The dynamic viscosity of the mixture of each fluid with Triton X-100 was investigated in the same temperature range, between 10 and $40{ }^{\circ} \mathrm{C}$ for water and between 0 and $80^{\circ} \mathrm{C}$ for Tyfocor ${ }^{\circledR}$ LS. A Newtonian behavior was also obtained as shown in Figures 4a and 4b with water and Tyfocor ${ }^{\circledR}$ LS, respectively. The results also showed that the addition of the surfactant to water or Tyfocor® LS increased their viscosities. Thus, the viscosity of distilled water increased by 34.6, 35.6, 56.2 and $68.7 \%$ at $10,20,30$ and $40{ }^{\circ} \mathrm{C}$, respectively. The viscosity of Tyfocor ${ }^{\circledR}$ LS was increased by 19.7, 29.2, 46.4 and $28.2 \%$ at $0,20,40$ and $80{ }^{\circ} \mathrm{C}$, respectively. Note that viscosity enhancement can be weighted according to the experimental uncertainty.

\section{Effect of concentration, temperature and base fluids}

Like for the used thermal fluids and base fluids, nanofluids prepared at the two lowest concentrations of MWCNTs (0.005 and 0.01 wt.\%) showed a Newtonian behavior, as shown in Figures 4a and 4b. However, a decrease in dynamic viscosity was shown for the two highest 
concentrations (0.05 and $0.1 \mathrm{wt} . \%)$ at low shear rates $\left(<200 \mathrm{~s}^{-1}\right)$, which became more significant with the increase in concentration, evidencing a shear-thinning phenomenon. For the highest shear rates, the nanofluids tend towards a Newtonian plateau. Similar results were obtained for the other temperatures, with a decrease in viscosity when temperature increased as expected. In addition, the nanofluid viscosity increased with the increase in nanotube content. In the following, the reported viscosity values consist in the average values for shear rates higher than $200 \mathrm{~s}^{-1}$, e.g. in the Newtonian region.

Adding nanoparticles in a liquid was reported to increase the fluid resistance to flow because of the greater friction occurring within the suspension [25]. Thus, once a nanofluid flows, a higher energy consumption is required (in comparison to the initial base fluid without nanoparticles) to overcome this augmentation in internal friction resistance [26], leading to the observed viscosity rising of the MWCNT nanofluids. Such a trend can also be enhanced with the presence of aggregates and their possible interaction. On the other hand, it is known that viscosity decreases with increasing temperature. This universal behavior in liquids is attributed to the lessening of molecular cohesive forces with increasing temperature, which results in a reduction in the shear stress, and then leads to a net reduction in viscosity [27].

Moreover, relative viscosity of nanofluids is presented in Figure 5 for the two base fluids. The relative viscosity $\mu_{\mathrm{r}}$ is defined as the ratio of the nanofluid viscosity to that of the mixture of heat transfer liquid and surfactant (at the same concentration than that used for the nanofluids, i.e. $5 \mathrm{wt} . \%$ of Triton $\mathrm{X}-100)$ at the same temperature. In Figure 5, the nanoparticle mass concentrations $\varphi_{\mathrm{m}}$ were converted into volume fractions, denoted $\varphi$, using densities (at $20^{\circ} \mathrm{C}$ ) of heat transfer liquids [18] and surfactant [19] for density evaluation of base fluid $\rho_{\mathrm{bf}}$ with mixing rule and the density of nanotubes $\rho_{\mathrm{np}}$, respectively, by using equation (1): 


$$
\varphi=\frac{\varphi_{m} \frac{\rho_{b f}}{\rho_{n p}}}{\left(1-\varphi_{m}\left(1-\frac{\rho_{b f}}{\rho_{n p}}\right)\right)}
$$

For both base fluids, an increase in relative viscosity with increasing volume concentration was observed. While the dynamic viscosity of the mixture of heat transfer fluids and surfactant and that of the nanofluids strongly depend on the temperature, it appears that the relative viscosity of the nanofluids is not significantly affected by temperature change considering the experimental uncertainty. For the sake clarity, in Figure 5, error bars that are linked to experimental uncertainty are reported for only one temperature.

Based on previous published works [5], [14], [20], concentration dependence of MWCNT-based nanofluid viscosities was compared to Maron \& Pierce [28,29] and modified Maron \& Pierce models [5] given by equations (2) and (3), respectively, in an attempt to understand the reason of the viscosity enhancement of nanofluids with concentration.

$$
\begin{gathered}
\mu_{r}=\left(1-\frac{\varphi}{\varphi_{\max }}\right)^{-2} \\
\mu_{r}=\left(1-\frac{\varphi_{a}}{\varphi_{\max }}\right)^{-2} \\
\varphi_{\max }=\frac{2}{0.321 r+3.02} \\
\varphi_{a}=\varphi \cdot\left(\frac{a_{a}}{a}\right)^{3-D}
\end{gathered}
$$

In these equations, $\varphi_{\max }$ is the maximum packing volume fraction which depends on the aspect ratio of the nanotubes [29] as indicated by equation (4). Based on this equation, the definition of the aspect ratio, $r=L / d$, L being the length of the MWCNTs and $d$ their diameter, and the average dimension 
of the nanotubes previously mentioned, $\varphi_{\max }$ is here equal to $3.61 \%[5,30]$. Also, in these equations, $\varphi_{a}$ is the effective volume fraction of the aggregates, if present. Its expression is given by equation (5) where $a_{a}$ and $a$ are the aggregate and primary nanoparticle radius, respectively. It should be mentioned that with tubes, the primary nanoparticle radius is assumed to correspond to the average length of tubes [30]. $D$ is the fractal index reported to be 2.1 for nanotubes [5].

It is observed from Figure 5 that the Maron \& Pierce model $[28,29]$ considerably deviated from experimental results, for both base fluids, except for nanofluids with low content in nanotubes and with water as base fluid. Such a trend can be attributed to the presence of aggregates, in particular for high content of nanotubes. In order to assess this issue, the size of aggregates evaluated by optical microscopy ealier were introduced in the equation 5, itself used in the modified Maron \& Pierce equation [5]. It was then observed that the model and the experimental data were in good agreement for water-based nanofluids for all concentrations, with a standard deviation of less than $5 \%$. That means that the role of aggregate size in viscosity enhancement for water-based nanofluids may be significant.

However, with Tyfocor ${ }^{\circledR}$ LS based nanofluids, introducing the corresponding aggregate size evaluated from optical microscopy in the modified Maron \& Pierce model [5] did not lead to a good prediction of the experiment data. In that case, due to the large number of aggregates (see Figure 2), interactions between them cannot be neglected. Viscosity enhancement is here not only attributed to aggregate size but also to inter-aggregate interactions. Such a result indicates that aggregates could also be present in great number at low content in nanotubes with Tyfocor ${ }^{\circledR}$ LS.

\section{Conclusions}


Carbon-based nanofluids were prepared with MWCNTs purified by a non-damaging method based on a combined thermal treatment in gas phase consisting of using nitrogen subsequent to chlorine at $1000^{\circ} \mathrm{C}$. The purified MWCNTs were dispersed in two base fluids, distilled water and a commercial mixture of propylene-glycol:water (around 40:60 wt.\%) with Triton X-100 as surfactant. The optimized content in surfactant for nanotube dispersion and stability was determined from optical microscopy. Then, the dynamic viscosity of the prepared purified MWCNT-based nanofluids was experimentally studied at temperatures between 0 and $80{ }^{\circ} \mathrm{C}$ and under shear rate range of $10-1000 \mathrm{~s}^{-}$ 1. A Newtonian behavior was observed for all nanofluids at low concentrations (0.005 and 0.01 wt.\%), and a shear-thinning behavior was found at higher concentrations (0.05 and 0.1 wt.\%). In addition, the dynamic viscosity enhancement of nanofluids with nanoparticles loading was compared to theoretical models. A good agreement was achieved with the modified Maron \& Pierce model [] with water-based nanofluids taking into account the size of aggregates evaluated from optical microscopy. For the commercial mixture of propylene-glycol:water, the viscosity enhancement is mainly governed by the large number of aggregates and their interaction rather than their size.

\section{Nomenclature:}

CNT: carbon nanotubes

MWCNT: multi-walled carbon nanotubes

rCNT: raw multi-walled carbon nanotubes

pCNT: purified multi-walled carbon nanotubes

TGA: Thermogravimetric analysis

TEM: Transmission electron microscopy

AAD\%: percentage absolute average deviations 


\section{English symbols:}

$a_{a}$ : aggregates radii (nm)

$a$ : primary nanoparticles radii (nm)

$d$ : diameter of nanotubes $(\mathrm{nm})$

$D$ : fractal index

$L$ : length of nanotubes (nm)

$r$ : aspect ratio of nanotubes

wt.\%: weight concentration

\section{Greek symbols:}

$\mu_{\mathrm{r}}$ : relative viscosity of nanofluids to corresponding heat transfer fluid+surfactant mixture $\varphi$ : volume fraction

$\varphi_{\mathrm{m}}$ : nanoparticle mass concentration

$\varphi_{\max }:$ maximum packing volume fraction

$\varphi_{a}$ : effective volume fraction of aggregates

$\rho_{\text {bf }}$ : base fluid density (g.m $\mathrm{m}^{-3}$ )

$\rho_{\text {np }}$ : nanoparticle density (g.m ${ }^{-3}$ )

\section{Subscripts:}

a: aggregates

bf: base fluid

m: mass concentration

max: maximum 
np: nanoparticles

Acknowledgments: SH and DC acknowledge the EU COST Action CA15119: Overcoming Barriers to Nanofluids Market Uptake for financial support in the participation of the $1^{\text {st }}$ International Conference on Nanofluids (ICNf) and the $2^{\text {nd }}$ European Symposium on Nanofluids (ESNf) held at the University of Castellón, Spain during 26-28 June 2019. DC is recipient of a postdoctoral fellowship from Xunta de Galicia (Spain).

This study is a contribution to the COST (European Cooperation in Science and Technology) Action CA15119: Overcoming Barriers to Nanofluids Market Uptake (NanoUptake).

Conflicts of Interest: The authors declare no conflict of interest.

\section{References}

[1] O. Mahian et al., "Recent advances in modeling and simulation of nanofluid flows-Part I: Fundamentals and theory", Phys. Rep, vol. 790, Feb. 2019, pp. 1-48, 2019. DOI: 10.1016/j.physrep.2018.11.004.

[2] S. M. S. Murshed and P. Estellé, "A state of the art review on viscosity of nanofluids", Renew. Sust. Energ. Rev., vol. 76, Sept. 2017, pp. 1134-1152, 2017. DOI: 10.1016/j.rser.2017.03.113.

[3] P. C. Mishra, S. Mukherjee, S. K. Nayak, and A. Panda, "A brief review on viscosity of nanofluids", Int. Nano Lett., vol. 4, Oct. 2014, pp. 109-120, 2014. DOI: 10.1007/s40089-0140126-3.

[4] S. Halelfadl, T. Maré, and P. Estellé, "Efficiency of carbon nanotubes water based nanofluids as coolants", Exp. Therm. Fluid Sci., vol. 53, Feb. 2014, pp. 104-110, 2014. DOI: 10.1016/j.expthermflusci.2013.11.010.

[5] S. Halelfadl, P. Estellé, B. Aladag, N. Doner, and T. Maré, "Viscosity of carbon nanotubes water-based nanofluids: Influence of concentration and temperature", Int. J. Therm. Sci., vol. 71, Sept. 2013, pp. 111-117, 2013. DOI: 10.1016/j.ijthermalsci.2013.04.013.

[6] M. D. Kathir Kaman, A. Sathishkumar, K. Sharma, C. Trivedi, and A. Singhal, "Rheological analysis of MWCNT, $\mathrm{TiO}_{2}, \mathrm{CuO}$ based Nano-Fluids under varying temperatures and concentrations", IOP Conf. Ser.: Mater. Sci. Eng., vol. 402, 01217815 pages, 2018. DOI:10.1088/1757-899X/402/1/012178. 
[7] A. Hameed et al., "Experimental investigation on synthesis, characterization, stability, thermophysical properties and rheological behavior of MWCNTs-kapok seed oil based nanofluid", $J$.

Mol. Liq., vol. 277, March 2019, pp. 812-824, 2019. DOI: 10.1016/j.molliq.2019.01.012.

[8] M. M. Derakhshan, M. A. Akhavan-Behabadi and M. Ghazvini, "Rheological characteristics, pressure drop, and skin friction coefficient of MWCNT-oil nanofluid flow inside an inclined microfin tube", Heat Trans. Eng., Vol. 36, Issue 17, pp. 1436-1446, 2015. DOI: 10.1080/01457632.2015.1010915.

[9] Babita, S. K. Sharma, and S. M. Gupta, "Synergic effect of SDBS and GA to prepare stable dispersion of CNT in water for industrial heat transfer applications", Mater. Res. Express, vol. 5, no 5, pp. 055511, 2018. DOI: 10.1088/2053-1591/aac579.

[10] F. Jabbari, A. Rajabpour, and S. Saedodin, "Viscosity of carbon nanotube/water nanofluid", $J$. Therm. Anal. Calorim., vol. 135, Issue 3, pp. 1787-1796, 2019. DOI: 10.1007/s10973-0187458-6.

[11] N. Singh , G. Chand and S. Kanagaraj, "Investigation of thermal conductivity and viscosity of carbon nanotubes-ethylene glycol nanofluids", Heat Trans. Eng., Vol. 33, Issue 9, pp. 821-827, 2012. DOI: $10.1080 / 01457632.2012 .646922$.

[12] M. Fasano and M. Bozorg Bigdeli, "Bottom up approach toward prediction of effective thermophysical properties of carbon-based nanofluids", Heat Trans. Eng., Vol. 39, Issue 19, pp. 1686-1697, 2018. DOI: 10.1080/01457632.2017.1384283.

[13] J. P. Vallejo, G. Żyła, J. Fernández-Seara, and L. Lugo, "Influence of Six Carbon-Based Nanomaterials on the Rheological Properties of Nanofluids", Nanomaterials, vol. 9, Issue 2, 146, 19 pages, 2019. DOI: 10.3390/nano9020146.

[14] M. A. Marcos et al., "MWCNT in PEG-400 nanofluids for thermal applications: A chemical, physical and thermal approach", J. Mol. Liq., vol. 294, Nov. 2019, 11161613 pages, 2019. DOI: 10.1016/j.molliq.2019.111616.

[15] N. Berrada et al., "Surface tension of functionalized MWCNT-based nanofluids in water and commercial propylene-glycol mixture", J. Mol. Liq., vol. 293, Nov. 2019, 1114737 pages, 2019. DOI: 10.1016/j.molliq.2019.111473.

[16] P. Estellé, S. Halelfadl, and T. Maré, "Thermophysical properties and heat transfer performance of carbon nanotubes water-based nanofluids", J. Therm. Anal. Calorim., vol. 127, Issue 3, pp. 2075-2081, 2017. DOI: 10.1007/s10973-016-5833-8.

[17] G. Mercier et al., "Selective removal of metal impurities from single walled carbon nanotube samples", New J. Chem., vol. 37, Issue 3, pp. 790-795, 2013. DOI: 10.1039/C2NJ41057E

[18] Tyfocor LS Technical Information available at https://tyfo.de/en/produkt/tyfocor-ls/ (last access January 2020).

[19] Triton ${ }^{\mathrm{TM}} \mathrm{X}-100$, Technical Information available at https://www.sigmaaldrich.com/catalog/product/sial/x100 (last access January 2020).

[20] D. Cabaleiro, P. Estellé, H. Navas, A. Desforges, and B. Vigolo, "Dynamic viscosity and surface tension of stable graphene oxide and reduced graphene oxide aqueous nanofluids", $J$. Nanofluids, vol. 7, no 6, pp. 1081-1088, 2018. DOI: 10.1166/jon.2018.1539.

[21] V. Jourdain, H. Kanzow, M. Castignolles, A. Loiseau, and P. Bernier, "Sequential catalytic growth of carbon nanotubes", Chem. Phys. Lett., vol. 364, no 1-2, pp. 27-33, 2002. DOI: 10.1016/S0009-2614(02)01309-X. 
[22] A. Jorio, M. A. Pimenta, A. G. S. Filho, R. Saito, G. Dresselhaus, and M. S. Dresselhaus, "Characterizing carbon nanotube samples with resonance Raman scatteringV, New J. Phys., vol. 5, 139, 18 pages, 2003. DOI: 10.1088/1367-2630/5/1/139.

[23] P. Keinänen et al., "Optimized dispersion quality of aqueous carbon nanotube colloids as a function of sonochemical yield and surfactant/CNT ratio", Heliyon, vol. 4, no 9, Sept. 2018, e00787 15 pages, 2018. DOI: 10.1016/j.heliyon.2018.e00787.

[24] J. Sengers and J. Watson, "Improved International Formulations for the Viscosity and ThermalConductivity of Water Substance", J. Phys. Chem. Ref. Data, vol. 15, no 4, pp. 1291-1314, 1986. DOI: $10.1063 / 1.555763$.

[25] J. P. Vallejo, S. Gomez-Barreiro, D. Cabaleiro, C. Gracia-Fernandez, J. Fernandez-Seara, and L. Lugo, "Flow behaviour of suspensions of functionalized graphene nanoplatelets in propylene glycol-water mixtures", Int. Commun. Heat Mass Transf., vol. 91, Feb. 2018, pp. 150-157, 2018. DOI: 10.1016/j.icheatmasstransfer.2017.12.001.

[26] D. Zhu, L. Wang, W. Yu, and H. Xie, "Intriguingly high thermal conductivity increment for $\mathrm{CuO}$ nanowires contained nanofluids with low viscosity", Sci. Rep., vol. 8, no 1, 5282 pp. 112, 2018. DOI: 10.1038/s41598-018-23174-z.

[27] J. F. Douglas, Fluid mechanics, $5^{\text {th }}$ ed. Harlow, England ; New York : Pearson/Prentice Hall, 2006.

[28] S.H. Maron and P.E. Pierce, "Application of Ree-Eyring generalized flow theory to suspensions of spherical particles", J. Colloid Sci., vol. 11, Issue 1, pp. 80-95, 1956. DOI: 10.1016/00958522(56)90023-X.

[29] S. Mueller, E. W. Llewellin, and H. M. Mader, "The rheology of suspensions of solid particles", P. Roy. Soc. A-Math. Phy., vol. 466, no 2116, pp. 1201-1228, 2010. DOI: 10.1098/rspa.2009.0445.

[30] P. Estellé, S. Halelfadl, N. Doner, and T. Maré, "Shear history effect on the viscosity of carbon nanotubes water-based nanofluid" », Curr. Nanosci., vol. 9, no 2, pp. 225-230, 2013. DOI: $0.2174 / 1573413711309020010$. 


\section{List of Figures}

Figure 1. Typical TEM bright field micrographs of (a) rCNT and (b) pCNT with $\mathrm{Cl}_{2}$ (at $1000^{\circ} \mathrm{C}$ for 2 h) followed by $2 \mathrm{~h}$ thermal treatment $\left(1000^{\circ} \mathrm{C}\right)$ under nitrogen.

Figure 2. Optical microscopy images of the nanofluids (0.1 wt.\% of MWCNTs) with water (a) and Tyfocor ${ }^{\circledR}$ LS (b) as base fluid and different concentration of Triton X-100 - from top to bottom, Triton X-100 content varying between 0.1 and 10 wt.\%.

Figure 3. Photos of the investigated MWCNT nanofluids containing 5\% of TritonX-100 with water (a) and Tyfocor ${ }^{\circledR}$ LS (b) after one month at rest - MWCNT content decreases from left to right.

Figure 4. Flow curves of pCNT based nanofluids at different concentrations, at $40{ }^{\circ} \mathrm{C}$ for water (a), and at $0{ }^{\circ} \mathrm{C}$ for Tyfocor ${ }^{\circledR}$ LS (b) used as solvent (with 5 wt.\% of Triton X-100 for both series).

Figure 5. Relative viscosity, $\mu_{\mathrm{r}}$, of (a) water and (b) Tyfocor® LS based nanofluids as a function of volume particle content, $\varphi$, and temperature. Error bars represent the experimental uncertainty. 


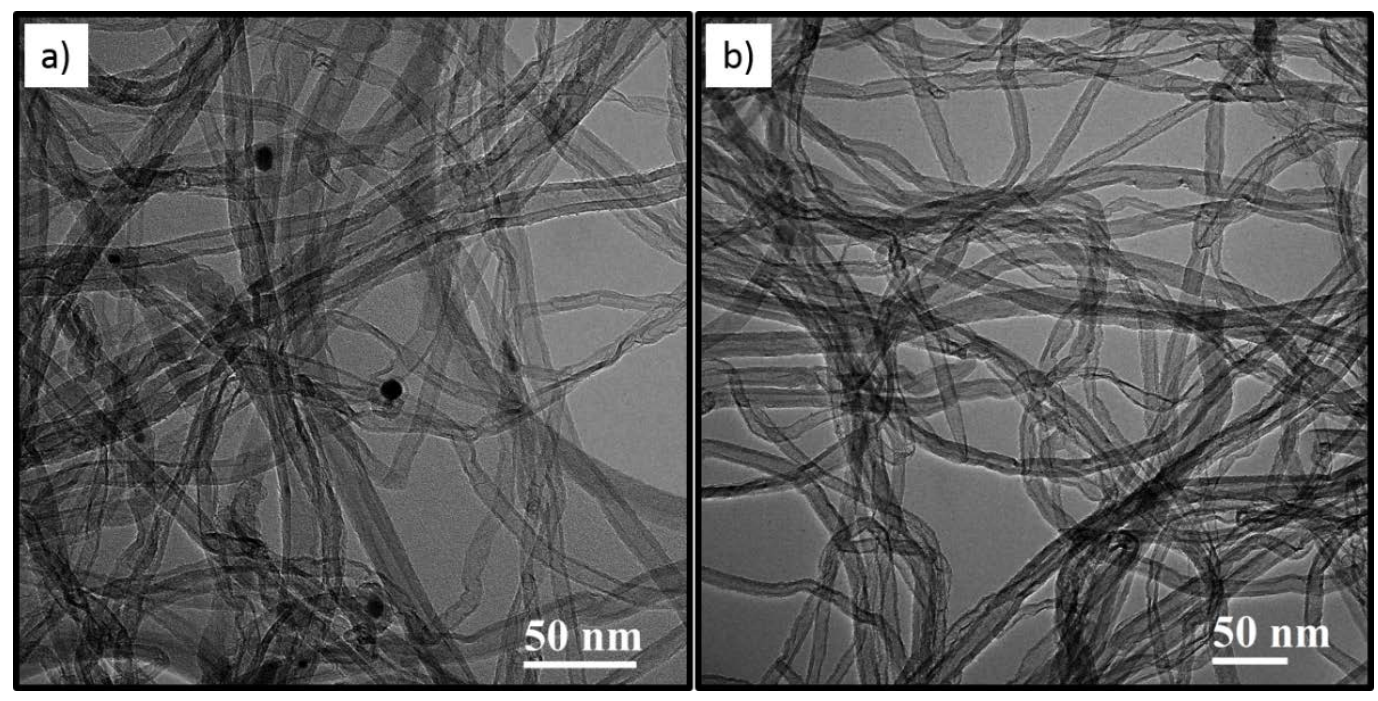

Figure 1. Typical TEM bright field micrographs of (a) $\mathrm{rCNT}$ and (b) $\mathrm{pCNT}$ with $\mathrm{Cl}_{2}$ (at $1000^{\circ} \mathrm{C}$ for 2 h) followed by 2 h thermal treatment $\left(1000^{\circ} \mathrm{C}\right)$ under nitrogen. 

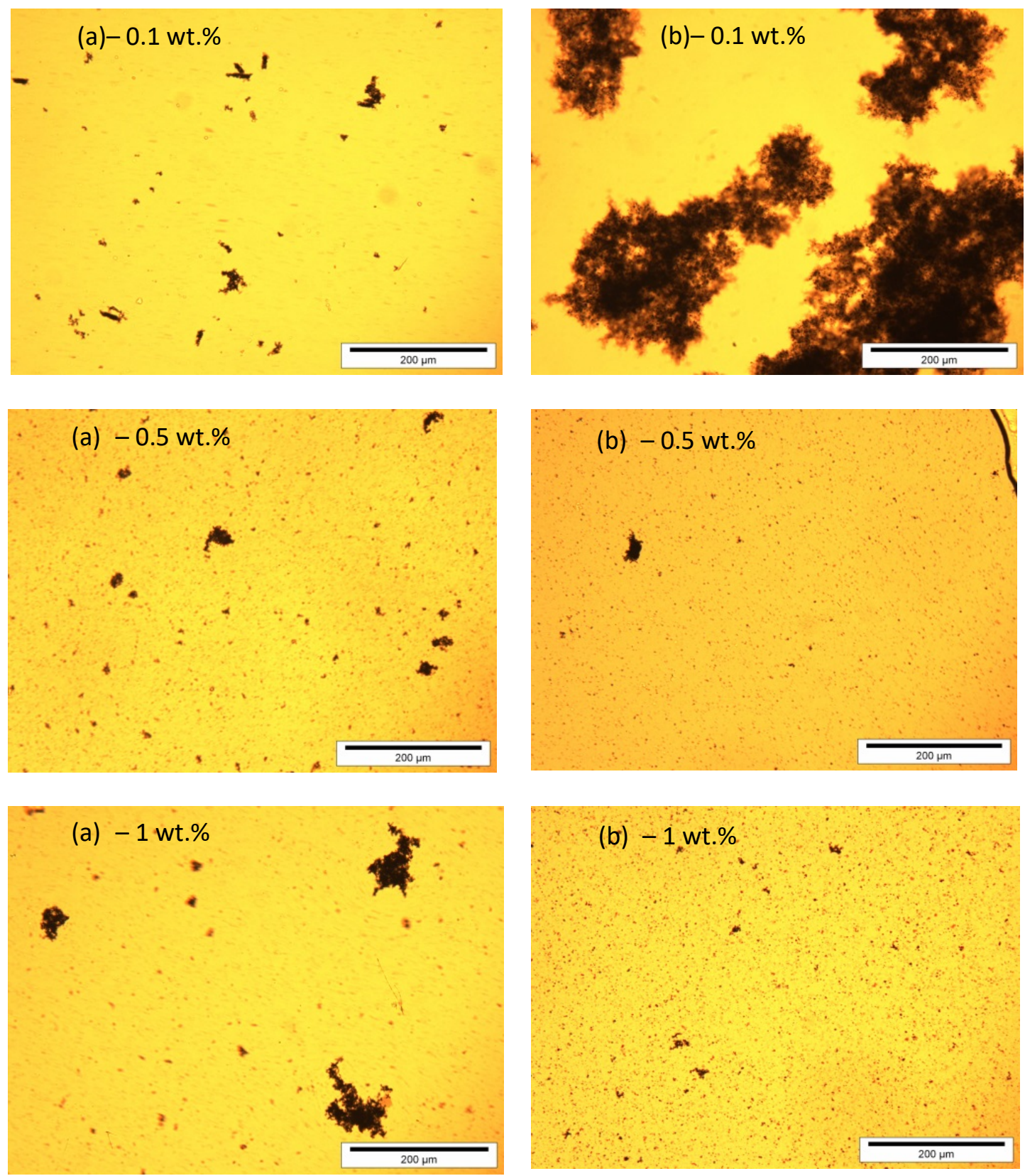

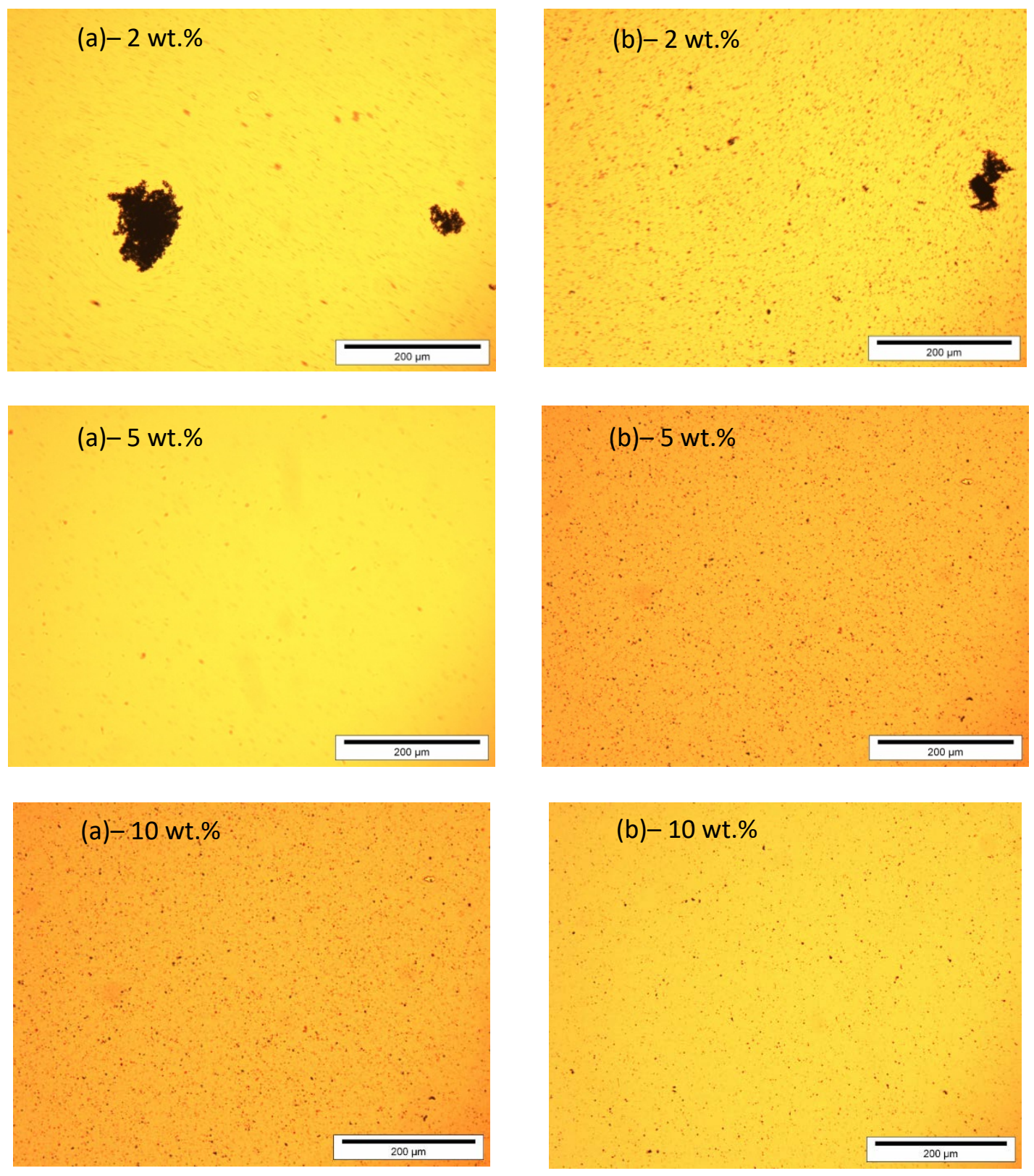

Figure 2. Optical microscopy images of the nanofluids (0.1 wt.\% of MWCNTs) with water (a) and Tyfocor ${ }^{\circledR}$ LS (b) as base fluid and different concentration of Triton X-100 - from top to bottom, Triton X-100 content varying between 0.1 and $10 \mathrm{wt} . \%$. 

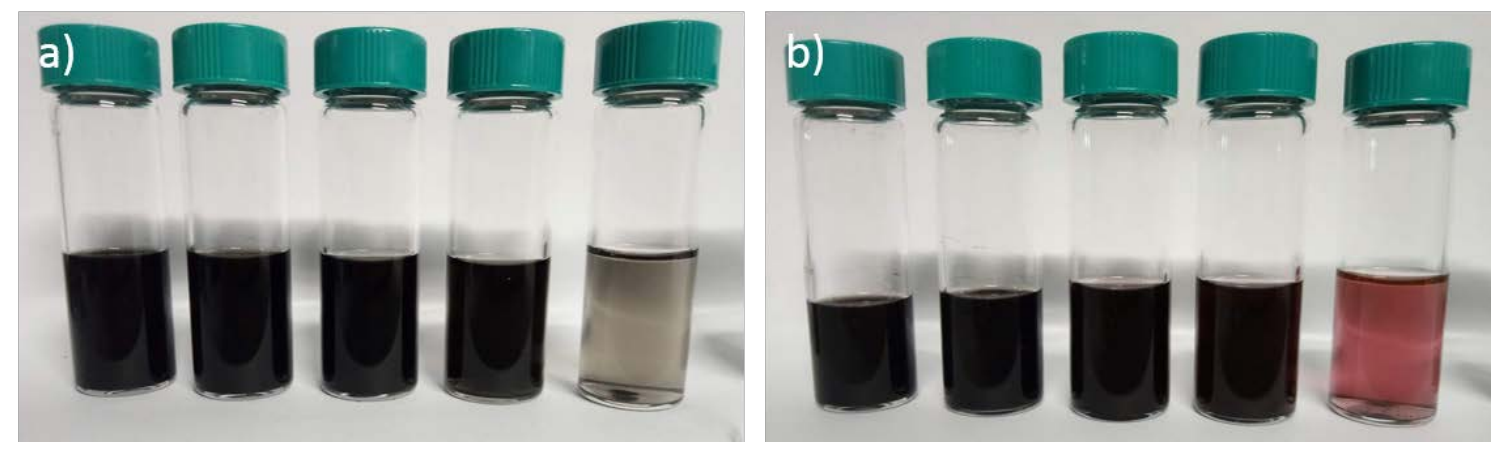

Figure 3. Photos of the investigated MWCNT nanofluids containing 5\% of TritonX-100 with water

(a) and Tyfocor ${ }^{\circledR}$ LS (b) after one month at rest - MWCNT content decreases from left to right. 

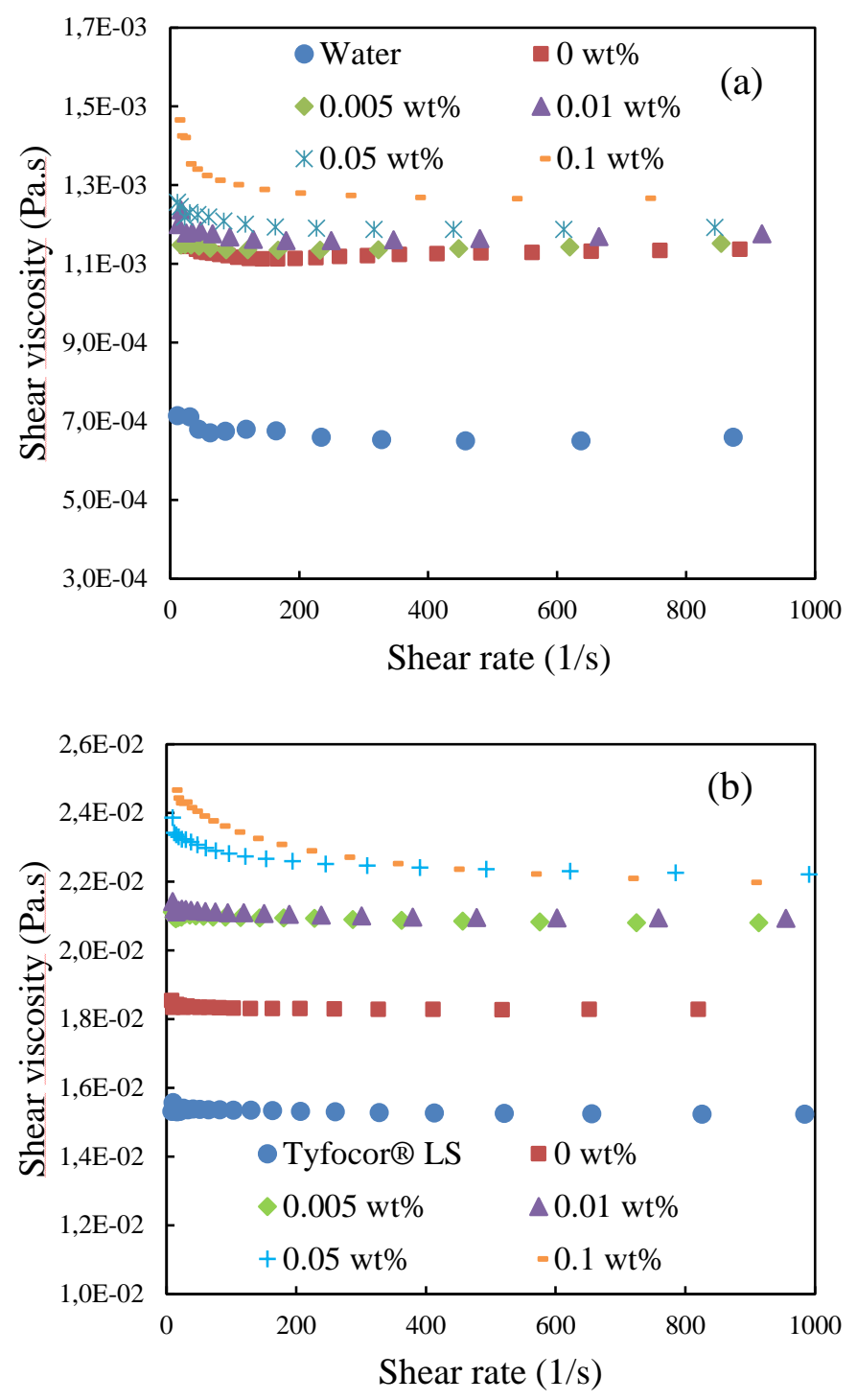

Figure 4. Flow curves of pCNT based nanofluids at different concentrations, at $40{ }^{\circ} \mathrm{C}$ for water (a), and at $0{ }^{\circ} \mathrm{C}$ for Tyfocor ${ }^{\circledR}$ LS (b) used as solvent (with 5 wt.\% of Triton X-100 for both series). 

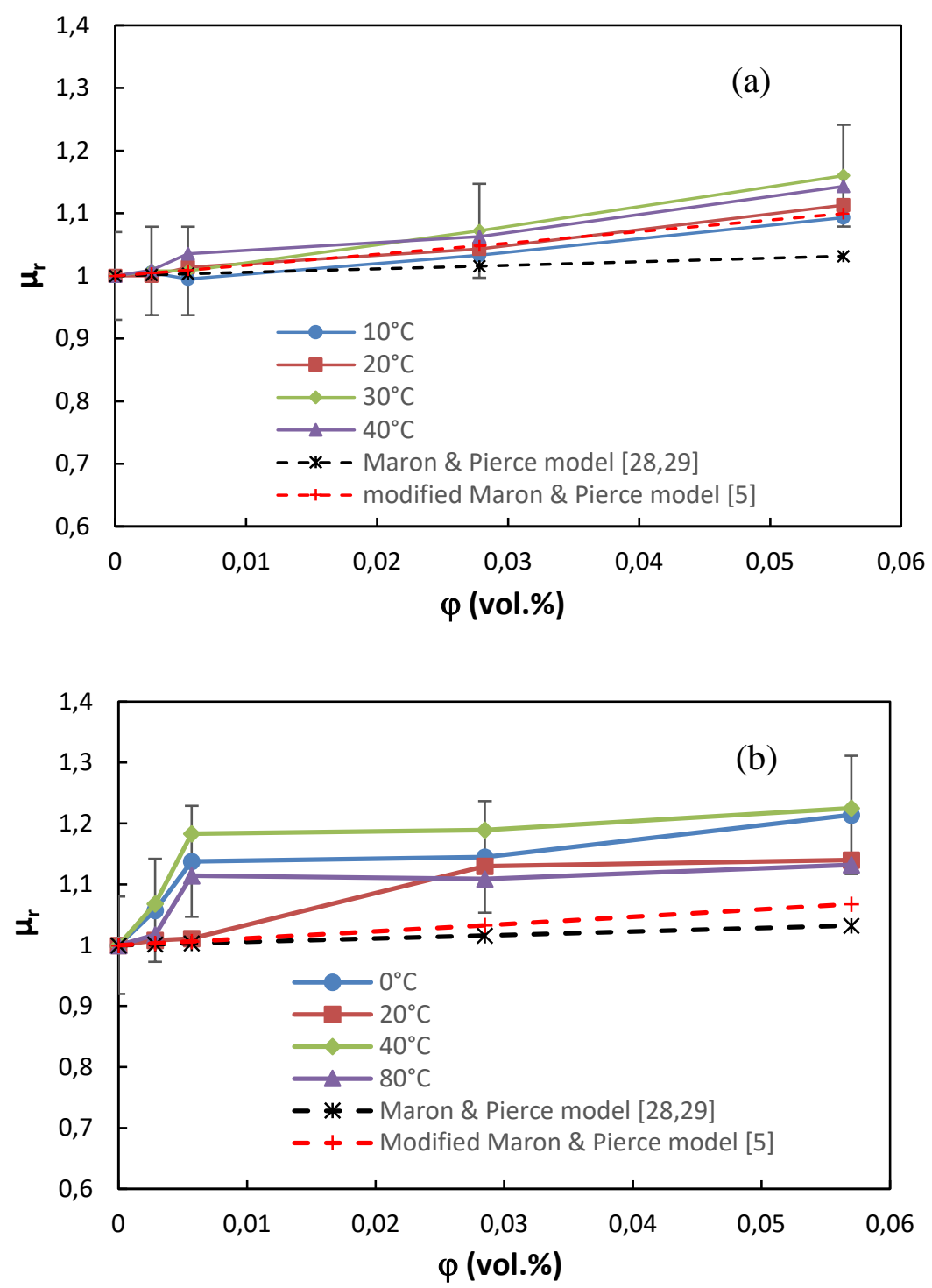

Figure 5. Relative viscosity, $\mu_{\mathrm{r}}$, of (a) water and (b) Tyfocor ${ }^{\circledR}$ LS based nanofluids as a function of volume particle content, $\varphi$, and temperature. Error bars represent the experimental uncertainty. 